\title{
DECAIMENTO DE BACTÉRIAS DO GRUPO COLIFORMES EM SOLOS COM COBERTURA VEGETAL E NU
}

Magno dos Santos Pereira1, Antonio Teixeira de Matos², Mateus Pimentel de Matos ${ }^{3}$, Pedro Lopes de Aguiar ${ }^{4}$

\section{RESUMO}

A fertirrigação é uma das alternativas para a disposição/tratamento de águas residuárias e traz, como grande vantagem, a possibilidade de aproveitamento agrícola dos nutrientes nelas contidos. Entretanto, é importante considerar o risco sanitário dessa prática, notadamente quando é utilizado esgoto doméstico submetido a tratamento inferior ao de nível terciário. Fatores como temperatura, incidência de raios UV, predação e competição podem proporcionar grande decaimento no número de micro-organismos exógenos no solo. Com a realização deste trabalho objetivou-se monitorar a sobrevivência e obter a taxa de decaimento de organismos indicadores, coliformes totais (CT) e coliformes termotolerantes ( $\mathrm{CF}-E$. coli), após 32 dias da aplicação de esgoto sanitário bruto em solo com cobertura vegetal e nu. A cobertura vegetal propiciou maior dispersão das bactérias no solo, proporcionando menor contagem na camada de 0-20 mm. Verificaram-se menores coeficientes de decaimento de bactérias do grupo coliformes totais que $E$. coli. No trigésimo segundo dia após a aplicação do esgoto sanitário, a contagem de $E$ coli passou a ser insignificante tanto nas áreas em que havia cobertura vegetal como em solo nu, estimando-se que se tornem desprezíveis após 6,6 e 13,0 dias respectivamente, após sua aplicação ao solo. A fertirrigação mostrou ser uma técnica adequada para tratamento/ disposição final de esgotos sanitários no que se refere à inativação de organismos patogênicos.

Palavras-chave: Águas residuárias, fertirrigação, micro-organismos indicadores

\section{ABSTRACT}

\section{COLIFORM BACTERIA DECAY IN PLANTED AND NON-PLANTED SOIL}

Fertigation is an alternative for the disposal/treatment of wastewater and provides the great advantage of potential application in agricultural use due to its contained nutrients. However, this practice can bring health risks, especially when using domestic sewage that has not undergone tertiary treatment. Factors such as temperature, UV rays, predation and competition can cause a great decay of exogenous microorganisms in the soil. The aim of this work was to monitor the survival and obtain the rate of decay of indicator organisms, total coliforms (TC) and fecal coliforms (FC - E. coli), after 32 days of applying raw sewage to planted and non-planted soil. The vegetation caused greater dispersion of bacteria in the soil, resulting in lower count 0-20 mm. A lower decay coefficient was observed for total coliforms than the E. coli. In the thirty-second day after sewage application, the E. coli count became insignificant in the planted and unplanted areas, estimating that they become negligible after 6.6 and 13.0 days, respectively, after application to the soil. Thus, the fertigation technique showed to be suitable for treatment/disposal of sewage with regard to the inactivation of pathogenic organisms.

Keywords: Fertigation, indicator microorganisms, wastewater

Recebido para publicação em 16/12/2013. Aprovado em 26/05/2014.

1 - Engenheiro Agrícola e Ambiental, Doutorando em Engenharia Agrícola, UFV - Campus Viçosa, MG, magno.eaa@gmail.com.

2 - Engenheiro Agrícola, D.S. em Solos e nutrição de Plantas, Prof. associado DEA/UFV - Campus Viçosa, atmatos@ufv.br.

3 - Engenheiro Agrícola e Ambiental, Doutorando em Engenharia Sanitária e Ambiental, UFMG, mateus.matos@ufv.br.

4 - Graduando em Agrícola e Ambiental, UFV - Campos Viçosa, MG, pedro.aguiar@ufv.br. 


\section{INTRODUÇÃO}

O lançamento in natura de esgotos domésticos em corpos d'água está associado a diversos efeitos deletérios no ambiente, tal como eutrofização, diminuição na concentração de oxigênio dissolvido (OD) e liberação de substâncias tóxicas no meio aquático (von SPERLING, 2005a; MATOS, 2010). Em países desenvolvidos, devido à capacidade de remoção de boa parte de poluentes em seus sistemas de tratamento, tem-se intensificado estudos relacionados às implicações da presença de disruptores endócrinos (hormônios e pesticidas) no ambiente aquático, e as possíveis formas de remoção (FONO; McDONALD, 2008; SANCHES et al., 2012). No Brasil e em outros países em desenvolvimento, o foco das agências ambientais permanece sob os micro-organismos patogênicos, tendo em vista a grande exposição da população sem acesso à água tratada e ao tratamento de esgoto, e a enfermidades associadas à falta de saneamento básico.

A presença, com alta incidência, de bactérias, vírus, ovos de vermes, Cryptosporidium e giárdia, em corpos d'água implica em riscos à saúde da população com doenças como cólera, febre tifoide, hepatites A e B, cisticercose, criptosporidíase e giardíase (DANIEL et al., 2001). No entanto, é inviável quantificar todos os micro-organismos de forma a verificar se alimentos ou a água oferecem riscos à saúde humana. Assim, de forma geral, a não ser que se queira investigar algum microorganismo específico, recorre-se a indicadores que tenham resistência semelhante à dos patógenos; que sejam facilmente detectáveis em laboratório; que não tenham capacidade de reprodução no ambiente; que sejam não patogênicos; e que estejam presentes apenas em ambientes contaminados, sendo de origem do trato intestinal de animais de sangue quente (BITTON, 2005). Nesse contexto, surgem as análises para monitoramento da E. coli, espécie do grupo dos coliformes termotolerantes (CF), anteriormente denominados fecais. Devido à ampla distribuição natural no ambiente, o grupo coliformes totais (CT) não pode ser utilizado como confirmação da contaminação do solo e água com dejetos humanos e animais (METCALF; EDDY, 2003).
De forma a controlar o número de organismos presentes em níveis considerados seguros, tem sido utilizados tratamentos com desinfecção com cloro, agentes oxidantes (ozônio e hipoclorito), raios UV e uso de membranas (DANIEL, 2001; PÁDUA, 2009). Lagoas de maturação têm sido uma alternativa eficiente na remoção de microorganismos de águas residuárias, proporcionando a entrada de raios UV em toda a massa de água, em decorrência de sua pequena profundidade. Os raios UV afetam a conformação do DNA, bloqueando a replicação das fitas, o que acaba levando à morte da célula do organismo patogênico (JUNGFER et al., 2007). Pode-se citar, também, como outros fatores preponderantes à ação antimicrobiana em lagoas de maturação, as altas temperaturas e o elevado $\mathrm{pH}$ do meio, condições desfavoráveis à sobrevivência dos patógenos (CAVALCANTI et al., 2001).

Uma forma simples de disposição final/ tratamento de águas residuárias é a fertirrigação. A aplicação de águas residuárias no solo possibilita o aproveitamento dos nutrientes pelas plantas, contribuindo para a melhoria nos atributos físicos, químicos e microbiológicos do solo, além de propiciar boas remoções e a inativação dos microorganismos patogênicos (COURACCI FILHO et al., 2003; RIBEIRO et al., 2009; BITTENCOURT et al., 2012).

O solo é um ambiente hostil aos microorganismos entéricos, pois reúne algumas das características indesejáveis à sua sobrevivência e reprodução. No solo, micro-organismos podem ficar retidos nos poros do solo, no sistema radicular das plantas, além de adsorvidos às cargas de superfície das argilas (DROZD; SCHWARTZBROD, 1996; ARAÚJO et al., 2010; FERNANDES et al., 2010; STEPHENS et al., 2010). Assim, como em lagoas de maturação, o ambiente superficial do solo está exposto à alta incidência de raios UV; altas temperaturas; $\mathrm{pH}$ adverso; competição por alimento com os micro-organismos autóctones, já adaptados ao meio; além de ficarem sujeitos à predação por outros organismos presentes no solo (SHUVAL et al., 1990; COURACCI FILHO et al., 2003).

O decaimento de grupos coliformes em sistemas de tratamento convencionais, na aplicação no solo e mesmo em estudos de autodepuração de corpos 
d'água, pode ser expresso, matematicamente, pela Lei de Chick (von SPERLING, 2005b). De acordo com a referida lei, a contagem de coliformes em um dado momento depende dos seus valores iniciais, do tempo transcorrido e do coeficiente de decaimento das bactérias no sistema, tal como apresentado na Equação 1. A influência da temperatura no decaimento de coliformes é, por sua vez, expressa na Equação 2.

$\mathrm{N}=\mathrm{N}_{0} x \mathrm{e}^{-\mathrm{K} . \mathrm{t}}$

$\mathrm{K}_{\mathrm{T}}=\mathrm{K}_{20} \times \theta^{(\mathrm{T}-20)}$

em que,

$\mathrm{N}$ é o número mais provável de coliformes (NMP/100 mL) num determinado tempo $t$, em dias, N0 é o número mais provável inicial (NMP/100 $\mathrm{mL}$ );

$\mathrm{K}_{\mathrm{T}}$ é o coeficiente de decaimento microbiano $\left(\mathrm{d}^{-1}\right)$, que varia de 0,5 a $1,5 \mathrm{~d}^{-1}$; e

$\theta$ é o coeficiente de temperatura, que tem valor de 1,07 (von SPERLING, 2005b).

A cobertura vegetal, por propiciar menores amplitudes térmicas e incidência de raios UV na superfície do solo, pode proporcionar menor taxa de decaimento microbiano no meio (BRIX, 1994). Algumas espécies de plantas são, no entanto, capazes de liberar substâncias inibidoras ao crescimento e reprodução de micro-organismos, as fitoalexinas (SMITH, 1996) e, segundo Ribas et al. (2008), bactérias nativas podem, também, liberar antibióticos no solo.

Com a realização deste trabalho, objetivou-se avaliar a sobrevivência e a taxa de decaimento de bactérias dos grupos coliformes no solo com cobertura vegetal e nu, após a aplicação do esgoto sanitário bruto.

\section{MATERIAL E MÉTODOS}

O experimento foi conduzido em condição de campo, em Cambissolo Háplico Tb distrófico latossólico (CXbd), na Área Experimental de Tratamento de Resíduos Urbanos (latitude 20 46' 20 " S, longitude $42^{\circ} 52^{\prime} 19^{\prime \prime} \mathrm{W}$, altitude de 677 m) do Departamento de Engenharia Agrícola da Universidade Federal de Viçosa - DEA/UFV.

O esgoto sanitário, utilizado no experimento, foi proveniente do Bairro Acamari e adjacências, sendo bombeado até a Área Experimental de Tratamento de Resíduos Urbanos do DEA/UFV via Estação Elevatória do DEA, instalada próxima à rede hidráulica de esgotamento sanitário do referido bairro.

$\mathrm{Na}$ área experimental foram estabelecidas 10 parcelas quadradas de $1 \mathrm{~m}^{2}$, sendo cinco delas desnudas e as outras cinco mantidas com cobertura vegetal (capim Tifton 85, plenamente desenvolvido), compreendendo os dois tratamentos testados no experimento Em cada parcela foi aplicado um volume de $500 \mathrm{~L}$ de esgoto sanitário bruto, com equivalência à aplicação de uma dose de $300 \mathrm{~kg} \mathrm{ha}^{-1}$ ano $^{-1}$ de nitrogênio total (NT), considerando-se uma concentração média de $60 \mathrm{mg}$ $\mathrm{L}^{-1}$ de NT no esgoto sanitário. Esse valor adotado é encontrado como limite superior na faixa de concentração típica de esgotos domésticos, como pode ser observado em von Sperling (2005a). A dose de nitrogênio foi estabelecida com base na recomendação de adubação no plantio de muitas culturas agrícolas (CFSEMG, 1999).

A aplicação do esgoto sanitário bruto foi feita em solo seco uma semana após o preparo da área, lentamente para permitir a infiltração do mesmo no solo, até atingir o volume pretendido numa aplicação única, utilizando-se para isso uma mangueira e baldes de volume conhecido, com aplicação manual e de forma homogênea sobre a superfície das parcelas. As amostras foram, então, coletadas na camada superficial de 0 a $20 \mathrm{~mm}$ e em 3 pontos aleatórios da parcela, perfazendo amostras compostas com aproximadamente $25 \mathrm{~cm}^{3}$, tendo sido feitas amostragens aos $0,2,4,8,16$ e 32 dias após a aplicação do esgoto sanitário. Após a coleta, as amostras foram encaminhadas ao Laboratório de Qualidade da Água do Departamento de Engenharia Agrícola, onde foram utilizados, em média, $2 \mathrm{~g}$ de solo para as análises de coliformes totais (CT) e termotolerantes (CF - E. coli), pelo método cromogênico, seguindo-se metodologia 
descrita por Matos (2012). A contagem inicial de CT e E. coli no esgoto sanitário aplicado foi de 1,89 x $10^{8}$ e $3,83 \times 10^{7} \mathrm{NMP} / 100 \mathrm{~mL}$, respectivamente.

A temperatura do solo foi monitorada, conjuntamente à coleta das amostras de solo, utilizando-se um termômetro digital do tipo termopar, da marca Incoterm e precisão de leitura de $\pm 1^{\circ} \mathrm{C}$. $\mathrm{O}$ monitoramento foi realizado nas profundidades de 0 a $10 \mathrm{~mm}$ (superfície) e 30 a $50 \mathrm{~mm}$ (subsuperficie), em três pontos aleatórios dentro de cada parcela, tanto nas áreas com cobertura vegetal como nas de solo nu.

$\mathrm{O}$ experimento foi conduzido segundo um delineamento em blocos casualizados (DBC), com parcelas subdivididas no tempo e dois tratamentos (parcelas com cobertura vegetal e de solo nu), foram utilizados testes estatísticos de comparação de médias de grupos (Teste Tukey), adotando-se um nível de significância de 5\%.

A estimativa da curva de decaimento de coliformes para os dois tratamentos ao longo do tempo foi realizada com ajuste do modelo exponencial de cinética de primeira ordem (Equação 1), utilizando o aplicativo Sigmaplot 10.0.

\section{RESULTADOS E DISCUSSÃO}

No Quadro 1, estão apresentadas a contagem de coliformes totais (CT) e coliformes termotolerantes
(CF - E. coli) nas áreas com cobertura vegetal e de solo nu. Verifica-se que a contagem tanto de coliformes totais como de E. coli, baixou sensivelmente já no dia 0 , decrescendo de 3 a 4 unidades log em ambos os casos. Esses resultados são indicativos de que o ambiente solo é inóspito para bactérias presentes no esgoto sanitário.

Considerando-se como referencial o dia 0 , ou seja, a partir do tempo em que o esgoto sanitário ficou em contato com o solo, verifica-se que, ainda assim, à exceção do coliformes totais em solo vegetado, houve grande remoção de bactérias do grupo coliformes (na faixa de 2 a 4 unidades $\log$ ), mesmo para um relativamente curto tempo de monitoramento (32 dias).

Comparando-se os resultados de remoção de coliformes obtidos em lagoas de maturação conjugadas a lagoas anaeróbias e facultativas, que são da ordem de 3 a 5 unidades $\log$ (von SPERLING; CHERNICHARO, 2005), verificase que as eficiências obtidas neste trabalho estão mais baixos, porém, foram obtidos em período de tempo bem mais curto, considerando-se que em lagoas o tempo de detenção hidráulica é de até 40 dias (CAVALCANTI et al., 2001). As diferenças entre os tempos podem ser ainda maiores caso se considere a contagem inicial no esgoto doméstico e não a contagem após sua incorporação ao solo.

Acredita-se que as diferenças encontradas nas

Quadro 1. Número mais provável de coliformes totais (CT) e coliformes termotolerantes (CF - E. coli) após diferentes tempos de aplicação do esgoto doméstico bruto em solo com cobertura vegetal (Veg) e solo nu $(\mathrm{Nu})$

\begin{tabular}{|c|c|c|c|c|}
\hline \multirow{2}{*}{$\begin{array}{l}\text { Tempo após a aplicação do } \\
\text { esgoto doméstico (dias) }\end{array}$} & \multicolumn{2}{|c|}{ Coliformes Totais } & \multicolumn{2}{|c|}{ Coliformes Termotolerantes (E. coli) } \\
\hline & Nu & Veg & $\mathbf{N u}$ & Veg \\
\hline & ----------- & 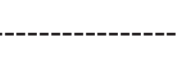 & NMP g ${ }^{-1}----$ & 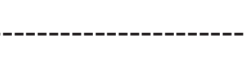 \\
\hline $\mathbf{0}$ & $1,4 \times 10^{5} \mathrm{a}$ & $5,9 \times 10^{4} \mathrm{~b}$ & $3,1 \times 10^{4} \mathrm{a}$ & $7,0 \times 10^{3} \mathrm{~b}$ \\
\hline 2 & $4,3 \times 10^{4} \mathrm{a}$ & $4,2 \times 10^{4} \mathrm{a}$ & $7,2 \times 10^{3} \mathrm{a}$ & $4,1 \times 10^{2} \mathrm{~b}$ \\
\hline 4 & $4,4 \times 10^{4} \mathrm{a}$ & $4,2 \times 10^{4} \mathrm{a}$ & $2,3 \times 10^{3} \mathrm{a}$ & $2,1 \times 10^{2} \mathrm{a}$ \\
\hline 8 & $3,2 \times 10^{4} \mathrm{a}$ & $3,3 \times 10^{4} \mathrm{a}$ & $2,2 \times 10^{2} \mathrm{a}$ & $2,1 \times 10^{2} \mathrm{a}$ \\
\hline 16 & $9,5 \times 10^{3} \mathrm{a}$ & $2,1 \times 10^{4} \mathrm{~b}$ & $1,2 \times 10^{2} \mathrm{a}$ & $2,5 \times 10^{2} \mathrm{a}$ \\
\hline 32 & $5,1 \times 10^{3} \mathrm{a}$ & $1,3 \times 10^{4} \mathrm{~b}$ & $0,0 \mathrm{a}$ & $0,0 \mathrm{a}$ \\
\hline
\end{tabular}

${ }^{(1)}$ médias seguidas de mesma letra (linhas) não diferem entre si, pelo teste de Tukey, em nível de 5\% de significância. 
contagens de coliformes, logo após a aplicação do esgoto sanitário no solo (dia 0 ), devam-se à maior dispersão do esgoto no solo vegetado, aprofundandose mais que quando aplicado em solo nu. No campo, foi observado que o esgoto apresentou menor capacidade de infiltração no solo nu que no que tinha cobertura vegetal, assim, possivelmente a população de bactérias ficou concentrada em camada mais fina de solo das parcelas de solo nu que nas de solo com cobertura vegetal, o que proporcionou maior densidade de bactérias por massa de solo. Outro fator que pode ter contribuído para que ocorressem essas diferenças é a liberação de exsudatos na rizosfera das plantas, cujo efeito seja bactericida (AVELAR et al., 2014).

Bactérias do grupo coliformes totais tiveram presença considerável no solo, em ambos os tratamentos (com cobertura vegetal ou solo nu), mesmo após 32 dias da aplicação do esgoto sanitário. Deve-se ponderar entretanto que, dentro do grupo coliformes totais, há a presença de espécies de vida livre, que são encontrados em ambientes não poluídos, como no próprio solo, tendo capacidade de reprodução nesse meio (von SPERLING, 2005a), o que pode levar à manutenção de contagens naturalmente altas no solo. Nas parcelas com cobertura vegetal, as contagens de CT foram maiores que as obtidas no solo nu na maior parte do tempo, o que dá indicativos de ser o ambiente da camada superficial em solo com cobertura vegetal mais adequado à sobrevivência dessas bactérias.
Tendo em vista que a temperatura é fator importante na sobrevivência de bactérias nas camadas superiores do solo, no Quadro 2 estão apresentados os valores obtidos no monitoramento efetuado ao longo dos 32 dias de experimentação.

Maiores temperaturas foram observadas na camada superficial do solo nu, devido à maior incidência de raios ultra-violeta não interceptados pelo dossel das plantas, conforme também observado por Oliveira et al. (2005), em áreas de cultivo agrícola.

Considerando-se somente a influência da temperatura na sobrevivência dos grupos coliformes, verificou-se que as menores temperaturas na camada superficial $(0$ a $10 \mathrm{~mm})$ e subsuperficial $(30$ a $50 \mathrm{~mm}$ ) do solo vegetado, aparentemente, contribuíram para a diminuição na população de $E$. coli, o mesmo não tendo acontecido com a de coliformes totais. A temperatura ótima de desenvolvimento de bactérias $E$. coli é de $39,0{ }^{\circ} \mathrm{C}$ (MADIGAN et al., 2010), muito mais alta que as encontradas no solo. A maior sobrevivência dos coliformes totais de vida livre deve-se à sua maior adaptação às condições naturais do solo.

Nas Figuras 1 e 2, estão apresentados as curvas e equações ajustadas, utilizando como o modelo a Equação 1, para o decaimento de coliformes totais e E. coli nos solos nu e com cobertura vegetal. Como as contagens de coliformes iniciais foram diferentes nos dois solos (Quadro 1), para propiciar melhores comparações foram feitas análises considerando valores relativos (N/N0).

Quadro 2. Temperatura média medida na camada de 0 a $10 \mathrm{~mm}$ e na camada de 30 a $50 \mathrm{~mm}$ dos solos analisados

\begin{tabular}{lcccc}
\hline & \multicolumn{2}{c}{ Área de solo nu } & \multicolumn{2}{c}{ Área com cobertura vegetal } \\
\cline { 2 - 5 } Dias & $\begin{array}{c}\text { Temperatura na } \\
\text { camada de 0 a 10 } \\
\mathbf{m m ~}\left({ }^{\circ} \mathbf{C}\right)\end{array}$ & $\begin{array}{c}\text { Temperatura na } \\
\text { camada de 30 a 50 } \\
\mathbf{m m}\left({ }^{\circ} \mathbf{C}\right)\end{array}$ & $\begin{array}{c}\text { Temperatura na } \\
\text { camada de 0 a 10 } \\
\mathbf{m m ~}\left({ }^{\circ} \mathbf{C}\right)\end{array}$ & $\begin{array}{c}\text { Temperatura na } \\
\text { camada de 30 a 50 } \\
\mathbf{m m}\left({ }^{\circ} \mathbf{C}\right)\end{array}$ \\
\hline $\mathbf{0}$ & 23,60 & 22,48 & 21,20 & 19,74 \\
$\mathbf{2}$ & 27,06 & 25,02 & 20,54 & 19,90 \\
$\mathbf{4}$ & 25,00 & 24,42 & 21,00 & 19,70 \\
$\mathbf{8}$ & 24,34 & 23,14 & 19,72 & 18,54 \\
$\mathbf{1 6}$ & 24,20 & 22,40 & 19,38 & 18,28 \\
$\mathbf{3 2}$ & 25,15 & 23,75 & 20,16 & 19,11 \\
\hline
\end{tabular}




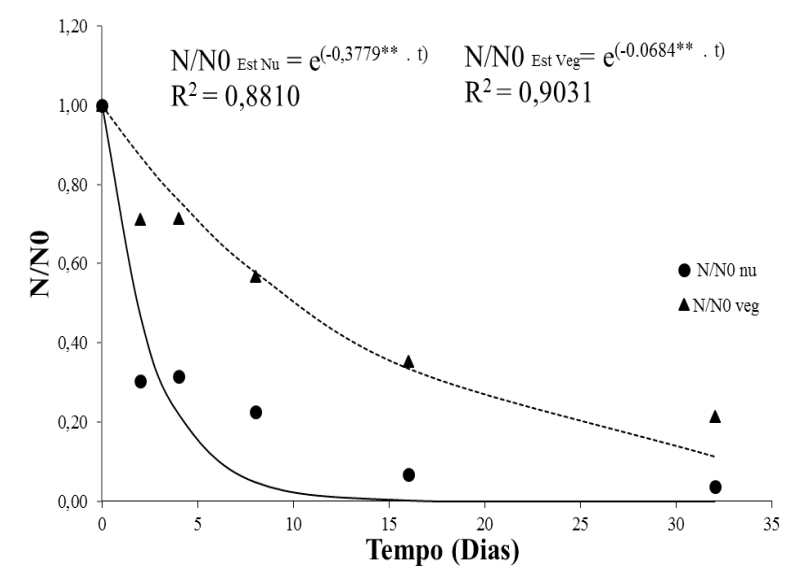

**Significativo em nível de 1\% de significância.

Figura 1. Valores observados (N/N0 ${ }_{\mathrm{Nu}}$ e N/N0 $\left.{ }_{\mathrm{Veg}}\right)$ e equações de decaimento ajustadas $(\mathrm{N} /$ $\mathrm{N} 0_{\text {Est Nu }}$ e N/N0 ${ }_{\text {Est Veg }}$ ) para estimativa da contagem relativa de coliformes totais como função do tempo decorrido após a aplicação do esgoto doméstico.

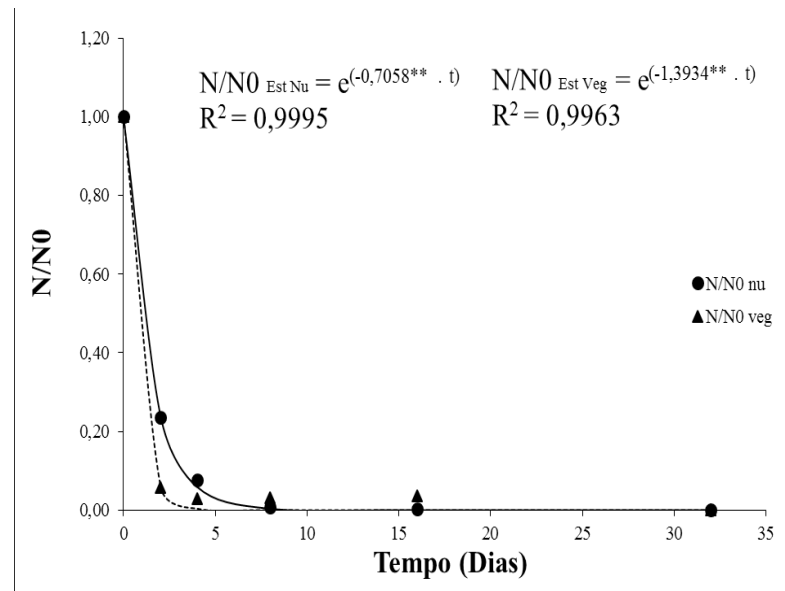

** Significativo em nível de 1\% de significância.

Figura 2. Valores observados $\left(\mathrm{N} / \mathrm{N} 0{ }_{\mathrm{Nu}}\right.$ e N/N0 $\left.{ }_{\mathrm{Veg}}\right)$ e equações de decaimento ajustadas (N/ $\mathrm{N} 0_{\text {Est Nu }}$ e N/N0 ${ }_{\text {Est Veg }}$ ) para contagem relativa de coliformes termotolerantes (E. coli) como função do tempo após a aplicação do esgoto doméstico.

O coeficiente de decaimento $\mathrm{K}$, obtido no ajuste da Equação 1 aos dados obtidos, é indicativo da tendência de progressão do número mais provável de organismos ao longo do tempo, no meio. Assim, verifica-se que a taxa de decaimento dos CT foi maior em solo nu que no de cobertura vegetal, possivelmente devido à ação da radiação solar direta (UV) que, sabidamente, é um agente nocivo aos micro-organismos. Já a taxa de decaimento de bactérias $E$. coli foi maior no solo com cobertura vegetal, provavelmente devido à maior competição, predação e a possível presença de substâncias inibidoras liberadas, no meio, pelas plantas. Shanab et al. (2010) observaram efeito antimicrobiano do extrato da Eichhornia crassipes, inclusive com efeito deletério à $E$. coli, indicando que essa espécie de planta tem substâncias que podem ser liberadas no meio, diminuindo a contagem de coliformes. Avelar et al. (2014) verificaram efetivo efeito antimicrobiano (coliformes totais e E. coli) de plantas de Mentha aquatica no tratamento de esgoto doméstico.

O valor obtido de $1,3934 \mathrm{~d}^{-1}$ para o coeficiente de decaimento de E. coli em solo com cobertura vegetal está dentro da faixa citada por von Sperling (2005b) para tratamento biológico de esgoto doméstico, sendo, no entanto, superior ao valor normalmente utilizados em estudos do decaimento de coliformes em rios, que é 1,0 d $\mathrm{d}^{-1}$. Oppa (2007) obteve coeficientes de decaimento de coliformes de $0,1 \mathrm{~d}^{-1}$, na vazão baixa, e de $5,0 \mathrm{~d}^{-1}$, em épocas de alta vazão, no rio Vacacaí Mirim. Vymazal (2005), por sua vez, estudando sistemas alagados construídos de escoamento subsuperficial horizontal, obteve valores de coeficiente de decaimento de 0,254 $\mathrm{d}^{-1}$ para CT e 0,389 $\mathrm{d}^{-1}$ para CF. Souza (2011), analisando um sistema de tratamento similar ao do presente trabalho, obteve valores de $0,4497 \mathrm{~d}^{-1} \mathrm{e}$ $1,5651 \mathrm{~d}^{-1}$, respectivamente para coliformes totais e termotolerantes. Ribas et al. (2008) verificaram menores contagens de $\mathrm{CF}$ em solos cultivados com feijão preto e na testemunha (sem cobertura vegetal) que em parcelas cultivadas com cevada, aveia e triticale. Segundo os autores, possivelmente, a menor sobrevivência no solo cultivado com feijão se deveu ao fato de se tratar de uma leguminosa que, com a incorporação de $\mathrm{N}_{2}$ atmosférico, favoreceu maior diversidade microbiológica no meio e, com isso, maior competição entre os micro-organismos, no meio.

A não detecção de E. coli cerca de 32 dias após a aplicação de esgoto doméstico no solo fornece indicativos do quão hostil é o solo à reprodução, crescimento e persistência de organismos entéricos. 
Como houve um hiato entre o décimo sexto dia e o trigésimo segundo dia, a não detecção de $\mathrm{CF}$ pode ter sido alcançada anteriormente. Utilizandose as equações ajustadas aos dados experimentais, verifica-se o tempo para remoção de 7 unidades log de E. coli, se considerada a contagem inicial no esgoto doméstico, ou de 4 unidades $\log$, se considerada a contagem obtida após sua aplicação no solo, é de 13,0 d em solo nu e de 6,6 d em solo com cobertura. Segundo Shuval et al. (1990), a sobrevivência de coliformes termotolerantes é de cerca de $20 \mathrm{~d}$ no solo, o que respalda os resultados encontrados neste trabalho. Diante dos resultados alcançados e dos valores citados em literatura, observa-se que o solo pode ser considerado meio capaz de inativar, com eficiência e rapidez, organismos patogênicos.

\section{CONCLUSÕES}

- Houve eficiente e rápida remoção de coliformes termotolerantes (E. coli) aplicados ao solo via esgoto sanitário bruto, estimando-se que contagens desprezíveis sejam obtidas após $13,0 \mathrm{~d}$ da sua aplicação em solo nu e 6,6 d em solo com cobertura;

- O coeficiente de decaimento de coliformes totais foi maior em solo nu, enquanto que o de E. coli foi maior no solo com cobertura vegetal;

- A fertirrigação mostrou ser uma técnica adequada para tratamento/disposição final de esgotos sanitários, no que se refere à inativação de organismos patogênicos.

\section{REFERÊNCIAS}

ARAÚJO, E.A.; ANDRADE, N.J.; SILVA, L.H.M.; CARVALHO, A.F.; RAMOS, A.M.; SÁ SILVA, C.A. Aspectos coloidais da adesão de microrganismos. Química Nova (Impresso), v.33, p.1940-1948, 2010.

AVELAR, F.F., MATOS, A.T., MATOS, M.P., BORGES, A.C. Coliform bacteria removal from sewage in constructed wetlands planted with Mentha aquatica. Environmental Technology,
2014. DOI: 10.1080/09593330.2014.893025.

BITTENCOURT, S.; SERRAT, B.M. AISSE, M.M.; MARIN, L.M.K.S.; SIMÃO, C.C. Aplicação de lodo de estação de tratamento de água (ETA) em solo degradado. Engenharia Sanitária e Ambiental, v.17, p.315-324, 2012.

BITTON, G. Wastewater Microbiology. Wiley, Third Edition. 2005.

BRIX, H. Functions of macrophytes in constructed wetlands. Wat. Sci. Tech. v.29, n.4., p.71-78, 1994

CAVALCANTI, P.F.F.; van HAANDEL, A.; KATO, M.T.; von SPERLING, M.; LUDUVICE, M.L.; MONTEGGIA, L.O. Pós-tratamento de efluentes anaeróbios por lagoas de polimento. In: CHERNICHARO, C.A.L.. (Org.). Póstratamento de efluentes de reatores anaeróbios. Belo Horizonte, MG: PROSAB, 2001, p.35-103.

CFSEMG - COMISSÃO DE FERTILIDADE DO SOLO DO ESTADO DE MINAS GERAIS - Recomendações para o uso de corretivos e fertilizantes em Minas Gerais. $5^{\mathrm{a}}$. aproximação. Viçosa, 1999. 359p.

DANIEL, L.A.; BRANDÃO, C.C.S.; GUIMARÃES, J.R.; LIBÂNIO, M.; LUCA, S.J. Processos de desinfecção e desinfetantes alternativos na produção de água potável. 1 . ed. São Carlos - SP: RIMA, 2001. 155p.

DROZD, C.; SCHWARTZBROD, J. Hydrophobic and electrostatic cell surface properties of Cryptosporidium parvum. Applied and Environmental Microbiology, v.62, n.4, p.12271232, 1996.

FERNANDES, N.M.G.; GINORIS, Y.P.; RIOS, R.H.T; BRANDÃO, C.C.S. Influência do $\mathrm{pH}$ de coagulação e da dose de sulfato de alumínio na remoção de oocistos de Cryptosporidium por filtração direta descendente. Engenharia Sanitária e Ambiental, v.15, n.4, p.375-384, 2010.

FONO, L.J.; McDONALD, H.S. Emerging compounds: A concern for water and wastewater utilities. Journal Awwa, American Water Association. November, v.100, n.11, p.50-57, 2008. 
JUNGFER, C.; SCHWARTZ, T.; OBST, U. UV-induced dark repair mechanisms in bacteria associated with drinking water. Water Research,. v.41, p.188-196, 2007.

MADIGAN, M.T.; MARTINKO, J.M.; DUNLAP, P.V.; CLARK, D.P. Microbiologia de Brock. 12. ed., Porto Alegre: Artmed, 2010. 1160p.

MATOS, A.T. Poluição Ambiental: Impactos no Meio Físico. Viçosa, MG: UFV, 2010. 260p.

METCALF \& EDDY. Wastewater Engineering: Treatment Disposal and Reuse. $4^{\mathrm{a}}$ ed. New York: McGraw-Hill, 2003, 1818p.

OLIVEIRA, M.L.; RUIZ, H.A.; COSTA, L.M. SCHAEFER, C.E.G.R. Flutuações de temperatura e umidade do solo em resposta à cobertura vegetal. Revista Brasileira de Engenharia Agrícola e Ambiental, v.9, n.4, p.535-539, 2005.

OPPA, L.F. Utilização de modelo matemático de qualidade da água para análise de alternativas de enquadramento do rio Vacacaí Mirim. Dissertação de Mestrado em Recursos Hídricos e Saneamento Ambiental. Programa de PósGraduação em Engenharia Civil. Universidade Federal de Santa Maria, Santa Maria, RS, 2007.

PÁDUA, V.L.(Org.). Remoção de microrganismos emergentes e microcontaminantes orgânicos no tratamento de água para consumo humano. 1. ed. Rio de Janeiro: ABES, 2009. 392p.

RIBAS, T.B.C.; FORTES NETO, P. Disposição no solo de efluentes de esgoto tratado visando à redução de coliformes termotolerantes. Revista Ambiente e Água. An interdisciplinary Journal of Applied Science, v.3, n.3. p.81-94, 2008.

RIBEIRO, M.S.; LIMA, L.A.; FARIA, F.H.S.; REZENDE, F.C.; FARIA, L.A. Efeitos de águas residuárias de café no crescimento vegetativo de cafeeiros em seu primeiro ano. Eng. Agríc., Jaboticabal, v.29, n.4, p.569-577, 2009.

SANCHES, S.; PENETRA, A.; RODRIGUES, A.; FERREIRA, E.; CARDOSO, V.V.; BENOLIEL, M.J.; CRESPO, M.T.; PEREIRA, V.J. CRESPO, J.G. Nanofiltration of hormones and pesticides in different real drinking water sources. Separation and Purification Technology, v.94, p.44-53, 2012.

SHANAB, S.M.M.; SHALABY, E.A.; LIGHTFOOT, D.A.; EL-SHEMY, H.A. Allelopathic Effects of Water Hyacinth [Eichhornia crassipes]. PLoS ONE, v.5, n.10, e13200. 2010.

SHUVAL, H.I.; ADIN, A. FATTAL, B. RAWITZ, $\mathrm{E}$; YEKUTIEL, $\mathrm{P}$. Integrated resource recovery wastewater irrigation in developing countries. World Bank Technical Paper number 51, s.d. 324p. 1990 (UNDP Project Management report number 6).

SMITH, J.C. Accumulation of phytoalexins: defence mechanism and stimulus response system. New Phytol, v.32, p.1-45, 1996.

SOUZA, P.R. Proposta de dimensionamento de leitos cultivados (wetlands) para tratamento de esgoto sanitário. Engenharia Ambiental, v.8, n.4, p.424-456, 2011.

STEPHENS, P.R.S.; OLIVEIRA, M.B.S.C.; RIBEIRO, F.C.; CARNEIRO, L.A.D. Virologia. In: MOLINARO, E.; CAPUTO, L.; AMENDOEIRA, $\mathrm{R}$. Conceitos e métodos para a formação de profissionais em laboratórios de saúde. Escola Politécnica de Saúde Joaquim Venâncio - EPSJV, Rio de Janeiro, 2010, p.125-220.

von SPERLING, M. Introdução à qualidade das águas e ao tratamento de esgotos: Princípios do Tratamento Biológico de Águas Residuárias. 3 ed. UFMG. Belo Horizonte, 2005a. 452p.

von SPERLING, M. Lodos ativados. Princípios do tratamento biológico de águas residuárias. 3 . ed. UFMG. Belo Horizonte, 2005b. 428p.

von SPERLING, M; CHERNICHARO, C.A.L. Biological wastewater treatment in warm climate regions. IWA Publishing. Londres, 2005. 1496 p.

VYMAZAL, J. Removal of Enteric Bacteria in Constructed Treatment Wetlands with Emergent Macrophytes: A Review. Journal of Environmental Science and Health, v.40, n.6-7, p.1355-1367, 2005. 